\title{
Yield responses of winter wheat to plant removal and to wheelings
}

\section{A. Darwinkel}

Research Station for Arable Farming and Field Production of Vegetables, Postbox 430, 8200 AK Lelystad, Netherlands

Received 25 October 1984; accepted 19 November 1984

Key-words: winter wheat, plant removal, cultural operations, wheelings, tramlines, yield compensation, border rows.

\section{Summary}

In winter wheat crops the removal of plants from two adjacent rows increased grain yields in two rows on either side of the path thus created. This yield compensation was achieved by increasing ear number per plant, grain number per ear and 1000grain weight. Yield compensation exceeded $80 \%$ if the plants had been removed at an early growth stage (GS); the yield compensation was smaller the later the plants were removed, being $14 \%$ after plants had been removed at GS 71 . The later the plants in bordering rows was greater, and consequently the yield loss was smaller. to yield compensation in the remaining border rows, with no effect when the plants had been removed after GS 32 . The contribution of grain number per ear to yield compensation followed a similar trend, with hardly any effect when plants were removed after GS 51. Frequent passes through the crop with a tractor led to almost total failure of grain production in the wheelings created. But this yield loss was partly compensated for by the increased yields of the rows next to the tracks. When tramlines were used for carrying out the cultural operations, the yield compensation by plants in bordering rows was greater, and consequently the yields loss was smaller. In commercial wheat production the yield losses resulting from cultural operations will be small: usually less than $150 \mathrm{~kg}$ grain per hectare.

\section{Introduction}

During the last decade, the grain yield of winter wheat has increased considerably. In the Netherlands, the increase in grain yield was approximately $1 \%$ per annum up to 1970 , and thereafter rose to approximately $3 \%$ per annum. The current national yield level is approximately $7 \mathrm{t} / \mathrm{ha}$. Such high-yielding wheat crops require many cultural operations, such as fertilizer dressing, the control of weeds, diseases and pests, and the application of growth regulators. Considerable physical damage is caused to plants as the tractor moves through the crop to apply these chemicals. 
Consequently, grain yield will be reduced (Hartmans \& Darwinkel. 1982). The timing and the number of treatments will determine the magnitude of the yield lost by the plants.

In intensive wheat production, the number of operations usually ranges from 5 to even more than 10 (Dilz et al., 1982). Plants in the wheelings will be repeatedly damaged, finally resulting in their death. However these moribund plants competed for nutrients, water and light while they were growing and in doing so, they may have restricted the compensatory ability of the plants growing in the border rows during early growth stages. Such wasteful competition may be prevented by making use of tramlines created by not drilling seed when applying cultural treatments.

Grain yield in cereals is composed of three yield components: the number of ears per unit area, the number of grains per ear, and the grain weight. Thus the mode of compensation can vary. The methods of compensation most likely to occur are tillering, ear formation, grain set and grain filling. It has been found that paths surrounding small-sized plots promote grain yield in the border rows, mainly by increasing the ear number (Austin \& Blackwell, 1980; Widdowson, 1973). Miller \& Mountier (1955) only found a yield increase in the first row adjacent to the path, with this increase being dependent on the width of the path.

The present experiments were undertaken to study the yield reduction and also the size and nature of yield compensation of winter wheat that arise as a result of tractors being driven through the crop. For carrying out cultural operations, the terms wheelings and tramlines are used promiscuously in this paper. For a right understanding of these terms:

- a wheeling is where a crop is drilled and subsequently damaged by a tractor wheel

- a tramline is where a track for a tractor is left by not drilling any seed.

\section{Materials and methods}

Three winter wheat experiments were carried out in 1980 and 1981. The cultivar Arminda was sown at mid-october at a row width of $12.5 \mathrm{~cm}$. Seed rate was 300 seeds per $\mathrm{m}^{2}$ to achieve an establishment of circa 200 plants per $\mathrm{m}^{2}$ after the winter, which is considered as being optimal for wheat growing in the Netherlands.

Experiment I (1980). In a field crop, the compensatory ability of wheat plants adjacent to simulated wheelings was examined in 3 border rows, sampled individually. A simulated path was created by removing plants in 2 adjacent rows at various dates or growth stages (GS, after Zadoks et al., 1974), viz 26/2 (GS 21), 23/4 (GS 30), 9/5 (GS 32), 22/5 (GS 39), 5/6 (GS 51), 20/6 (GS 61) and 5/7 (GS 71), respectively.

In 6 replicates, plants from the 3 border rows (each row being $2 \mathrm{~m}$ long) were sampled from both sides of the path: the first row on either side of the path was designated row 1; plants from the next row in (row 2) were also collected separately, as were plants from the third row (row 3 ). The control plots represents 8 rows, because no plant removal took place. The extent to which the treated plots were able to compensate for the removing of plants in 2 adjacent rows is expressed as: 
yield compensation $(\%)=100\left(Y_{\mathrm{t}}-3 / 4 Y_{\mathrm{c}}\right) / 1 / 4 Y_{\mathrm{c}}$

in which $Y_{\mathrm{t}}=$ total grain yield of the treatment (6 rows)

$Y_{\mathrm{c}}=$ total grain yield of the control plot (8 rows).

Experiment II (1981) was similar to Experiment I. In 6 replicates, plants were removed from 2 adjacent rows on 5 dates, viz 24/3 (GS 22), 22/4 (GS 30), 12/5 (GS 32), 1/6 (GS 51) and 22/6 (GS 67), respectively. In this experiment, plants in 2 rows on both sides of the path were sampled for analysis. Analogous to experiment I, row 1 was the first row on either side and row 2 was the second row on either side of the path. Correspondingly, the control plot consisted of 6 rows.

Experiment III (1981) was sown on 13 October 1980. Each of the 5 replicated blocks comprised 10 random plots measuring a net size of $3 \times 12=36 \mathrm{~m}^{2}$. In 5 of these plots, one pair of adjacent rows was not sown (this was done by blocking the coulters behind the tractor wheels). In this way, uncropped paths or tramlines were created, later used as a pathway for tractor wheels (width of tyres $22.5 \mathrm{~cm}$ ). In the other 5 plots of each replicate a tractor was driven through the crop; plants of two rows were repeatedly run over (and consequently damaged) by the tractor wheels, creating wheelings with a width comparable to that of the tramlines. To simulate increasingly intensive management systems, the plots were subjected to different regimes of tractor passes during the growth period (from GS 31 to GS 75); the number passes were $0,3,5,7$ and 9 , respectively. The plots with undisturbed crop growth (no pathway, no tractor pass) act as control plots. Each plot included 2 pathways; harvest was done by combine. A pre-harvest sample was taken from each plot to analyse the mode of yield compensation in border rows adjacent to a tramline or to a wheeling. Two rows, each $62.5 \mathrm{~cm}$ long, were sampled on either side; in the control plots 6 corresponding rows were sampled.

After harvest, all plant samples were analysed for grain yield, ear number and 1000 -grain weight. The numbers of grains per ear and per unit area were also calculated. Grain yields were converted to a moisture content of $17 \%$. All experiments were carried out on the fertile, well-textured marine clay soil of the newly reclaimed Flevopolder near Lelystad. Cultural measures in all experiments were those of normal cereal growing. The direction of sowing was from east to west in 1980 and from north to south in 1981.

\section{Results}

The effect of removing plants in 2 adjacent rows on grain yield was studied in the 3 border rows in Experiment I. Data are presented in Table I. It can be seen that the time of plant removal clearly influenced subsequent grain yield and grain yield formation: the later the plants were removed, the lower the grain yield per plot. The ear number per plot decreased when plants were removed up to GS 39; subsequent removal of plants had no effect on ear number. Grain number per ear was slightly 


\section{A. DARWINKEL}

Table 1. Yield and yield components in 6 neighbouring rows of $1 \mathrm{~m}$ length, 3 on each side of open spaces obtained by removing 2 adjacent rows of plants at different times during crop growth; the control plots include 8 rows. Net plot size is $1 \mathrm{~m}^{2}$. Data from Experiment $\mathrm{I}$.

\begin{tabular}{|c|c|c|c|c|c|c|c|}
\hline \multicolumn{2}{|c|}{ Time of plant removal } & \multirow{2}{*}{$\begin{array}{l}\text { Grain } \\
\text { yield } \\
\left(\mathrm{g} / \mathrm{m}^{2}\right)\end{array}$} & \multirow{2}{*}{$\begin{array}{l}\text { Ear } \\
\text { number } \\
\text { per } \mathrm{m}^{2}\end{array}$} & \multirow{2}{*}{$\begin{array}{l}\text { Grain } \\
\text { number } \\
\text { per ear }\end{array}$} & \multirow{2}{*}{$\begin{array}{l}1000- \\
\text { grain } \\
\text { weight }(g)\end{array}$} & \multirow{2}{*}{$\begin{array}{l}\text { Grain } \\
\text { number } \\
\text { per } m^{2}\end{array}$} & \multirow{2}{*}{$\begin{array}{l}\text { Yield } \\
\text { compen- } \\
\text { sation }(\%)\end{array}$} \\
\hline date & growth stage & & & & & & \\
\hline control plot & - & 893 & 530 & 39.1 & 43.1 & 20710 & - \\
\hline $26 / 2$ & 21 & 853 & 465 & 41.2 & 44.3 & 19270 & 82 \\
\hline $23 / 4$ & 30 & 814 & 444 & 40.9 & 44.8 & 18180 & 65 \\
\hline $9 / 5$ & 32 & 820 & 423 & 42.6 & 45.7 & 17990 & 67 \\
\hline $22 / 5$ & 39 & 767 & 397 & 41.9 & 46.3 & 16560 & 44 \\
\hline $5 / 6$ & 51 & 735 & 389 & 40.8 & 46.4 & 15830 & 29 \\
\hline $20 / 6$ & 61 & 730 & 397 & 39.4 & 46.7 & 15600 & 27 \\
\hline $5 / 7$ & 71 & 702 & 397 & 39.5 & 45.1 & 15570 & 14 \\
\hline
\end{tabular}

Table 2. Yield and yield components of the first, second and third border rows, each 1 metre long $(=$ $0.125 \mathrm{~m}^{2}$ ), after plants had been removed in 2 adjacent rows, and in rows of the control plots. Mean data from the various removal treatments of Experiments I and II. Weights are given in $\mathrm{g}$ at $17 \%$ moisture content.

Row 1 Row 2 Row 3 control

\begin{tabular}{|c|c|c|c|c|}
\hline \multicolumn{5}{|l|}{ a. grain yield } \\
\hline Expt. I (1980) & 141 & 137 & 111 & 112 \\
\hline Expt. II (1981) & 155 & 123 & - & 109 \\
\hline \multicolumn{5}{|l|}{ b. ear number } \\
\hline Expt. I (1980) & 71 & 73 & 65 & 66 \\
\hline Expt. II (1981) & 83 & 72 & - & 70 \\
\hline \multicolumn{5}{|l|}{ c. 1000 -grain weight } \\
\hline Expt. I (1980) & 47.0 & 45.6 & 44.1 & 43.1 \\
\hline Expt. II (1981) & 42.2 & 40.5 & - & 38.1 \\
\hline \multicolumn{5}{|c|}{ d. grain number per ear } \\
\hline Expt. I (1980) & 42.7 & 40.9 & 39.2 & 39.1 \\
\hline Expt. II (1981) & 44.7 & 42.1 & - & 40.5 \\
\hline \multicolumn{5}{|c|}{ e. grain yield per ear } \\
\hline Expt. I (1980) & 1.99 & 1.87 & 1.71 & 1.69 \\
\hline Expt. II (1981) & 1.88 & 1.71 & - & 1.55 \\
\hline
\end{tabular}

enhanced by plant removal, up until the plants were at GS 61. 1000-grain weight increased after all plant removals, but was especially enhanced if the plants were removed at some time between ear emergence (GS 51) and flowering (GS 61). Compensation for grain yield decreased considerably the later the plants were removed.

Table 2 shows main data of the yield and yield components of 3 adjacent border rows from Experiment I and the 2 border rows of Experiment II. In Experiment I no differences were measured in yield characteristics between the third row and the rows of the control plot. This means that compensatory effects were only found in the 2 border rows (row 1 and row 2 ). For this reason, a third row was not sampled in Experiments II and III. 
Table 3. Grain yields per plot $\left(=36 \mathrm{~m}^{2}\right)$, grain yields per hectare and yield losses per hectare (operation width $12 \mathrm{~m}$ ), in $\mathrm{kg}$ at $17 \%$ moisture content. Results from Experiment III.

\begin{tabular}{|c|c|c|c|c|c|c|}
\hline \multirow{2}{*}{$\begin{array}{l}\text { Number of } \\
\text { operations }\end{array}$} & \multicolumn{2}{|c|}{ Grain yield (kg/plot) } & \multicolumn{2}{|c|}{ Grain yield (kg/ha) } & \multicolumn{2}{|c|}{ Yield losses (kg/ha) } \\
\hline & wheeling & tramline & wheeling & tramline & wheeling & tramline \\
\hline 0 & $32.15^{*}$ & 31.60 & 8930 & 8890 & - & 40 \\
\hline 3 & 31.70 & 31.70 & 8900 & 8900 & 30 & 30 \\
\hline 5 & 31.00 & 31.25 & 8850 & 8870 & 80 & 60 \\
\hline 7 & 30.45 & 31.00 & 8810 & 8850 & 120 & 80 \\
\hline 9 & 30.20 & 30.70 & 8790 & 8830 & 140 & 100 \\
\hline
\end{tabular}

* Control plot.

The compensation for grain yield in row 1 was approximately double that of row 2. All yield characteristics in row 1 exceeded those of row 2, except for the ear number in Experiment I. The reason for this low ear number in row 1 of Experiment $I$ is not clear, but in this experiment row 1 was situated immediately adjacent to the ruts made by tractor wheels at sowing, and poor emergence is often found in this row, leading to poor plant establishment.

The grain yield per plot from Experiment III, as shown in Table 3, decreased as the number of operations increased. In the control plot, grain yield was $32.15 \mathrm{~kg}$ per plot, corresponding to nearly $9 \mathrm{t}$ per hectare. In a crop with wheelings, grain yield per plot was $30.20 \mathrm{~kg}$ after 9 operations; this is a yield loss of nearly $2 \mathrm{~kg}$ per plot. The creation of tramlines at sowing reduced grain yield by circa $0.5 \mathrm{~kg}$ per plot. When tramlines were used to carry out 9 cultural operations, yield reduction was $1.45 \mathrm{~kg}$ per plot. Thus, in both cases grain yield was reduced after each treatment, but the yield loss was smallest when tramlines were used.

The yield losses per hectare, due to wheel passes through the crop stand, depend on the operation width. For nitrogen application this width usually varies from 6 to $24 \mathrm{~m}$, for sprayings from 12 to $24 \mathrm{~m}$. For calculating yield losses for a field an operation width of $12 \mathrm{~m}$ was adopted. To obtain the grain yield per hectare, the actual yield of each plot must be added to the yield of 3 control plots. As can be seen in Table 3, yield losses were found to vary between 30 and $140 \mathrm{~kg}$ per hectare; in none of the plots subjected to tractor passes did the yield loss exceed $2 \%$ vis-à-vis the control. Most damage was suffered after 9 operations; yield losses were $100 \mathrm{~kg}$ per hectare with tramlines but were $140 \mathrm{~kg}$ per hectare with wheelings.

The net size of each plot included 24 rows. In the plots a pathway corresponding to $2 \times 2$ adjacent rows were used for the tractor passes. Using the grain yield in the control plot, a grain yield of $(20: 24) \times 32.15=26.80 \mathrm{~kg}$ per plot could be expected if no compensation took place. As can be seen from Table 3, grain yields were higher and a considerable compensation in grain yield occurred. To examine the mode of the compensation for grain yield, subsamples from 4 rows, two on either side of a tramline or a wheeling were taken for analysis; based on the data of Table 2 these 4 rows were assumed to compensate for the corresponding 6 rows of the control plot. Data about yield characteristics are presented in Table 4 . Border rows clearly out- 


\section{A. DARWINKEL}

Table 4. Yield and yield components of 4 bordering rows, 2 rows on each side of a wheeling or a tramline after various operations, in comparison to the control plot including 6 rows (Experiment III). Mean data for 1 row of 1 metre length $\left(=0.125 \mathrm{~m}^{2}\right)$.

\begin{tabular}{|c|c|c|c|c|c|c|}
\hline & $\begin{array}{l}\text { Grain } \\
\text { yield }(\mathrm{g})\end{array}$ & $\begin{array}{l}\text { Ear } \\
\text { number }\end{array}$ & $\begin{array}{l}\text { Grain } \\
\text { number } \\
\text { per ear }\end{array}$ & $\begin{array}{l}1000- \\
\text { grain } \\
\text { weight }(g)\end{array}$ & $\begin{array}{l}\text { Total } \\
\text { grain } \\
\text { number }\end{array}$ & $\begin{array}{l}\text { Yield } \\
\text { compen- } \\
\text { sation (\%) }\end{array}$ \\
\hline Rows in control plots & 113.1 & 79.6 & 40.7 & 35.0 & 3234 & - \\
\hline \multicolumn{7}{|c|}{ Rows bordering wheelings } \\
\hline 3 operations & 157.1 & 104.4 & 42.0 & 36.0 & 4366 & 78 \\
\hline 5 operations & 148.9 & 95.3 & 42.1 & 37.2 & 3999 & 63 \\
\hline 7 operations & 144.6 & 92.0 & 42.8 & 36.7 & 3934 & 56 \\
\hline 9 operations & 145.8 & 88.3 & 42.9 & 38.5 & 3827 & 58 \\
\hline \multicolumn{7}{|c|}{ Rows bordering tramlines } \\
\hline 0 operations & 163.6 & 107.8 & 42.1 & 36.0 & 4543 & 89 \\
\hline 3 operations & 163.7 & 106.6 & 42.1 & 36.6 & 4468 & 89 \\
\hline 5 operations & 161.4 & 106.5 & 42.3 & 35.9 & 4492 & 85 \\
\hline 7 operations & 156.6 & 107.6 & 40.7 & 36.0 & 4412 & 77 \\
\hline 9 operations & 156.2 & 103.5 & 41.2 & 36.7 & 4263 & 76 \\
\hline
\end{tabular}

yielded the rows of the control plot; this mainly resulted from an increased ear number and, to a small extent, from a higher number of grains per ear and a higher 1000grain weight. The presence of tramlines enhanced grain production, and the yield loss resulting from the higher number of operations was smaller. From Table 4 potential yield loss for a pathway could be calculated as being $2 \times 113.1=226.2 \mathrm{~g}$ of grain per metre row length. The enhanced grain yields of plants in the 4 bordering rows compensated for this yield loss from $58 \%$ to $78 \%$ in the plots with wheelings, and from $76 \%$ to $89 \%$ in those with tramlines.

\section{Discussion}

In a cereal crop, the yield components can vary widely. In widely spaced crops, plants have favourable conditions for growth, resulting in high numbers of ears per plant and of grains per ear (Darwinkel, 1978). Removing plants in 2 adjacent rows increased the irradiance and supply of water and minerals to the bordering rows. As a result, these border rows produced a considerably higher yield, which largely compensated for the uncropped paths thus created (Table 1). This compensation must have been achieved by the 2 bordering rows, because no yield increase was found in the third row (Table 2).

In the outer rows of experimental plots, Austin \& Blackwell (1980) and Widowson (1973) found a substantial increase in grain yield; the effect of a path to delineate plots was mainly confined to the row bordering it, and the yield increase of the 2 nd and the 3 rd rows in from the outer row was small. The yield increase was largely caused by a higher ear number per plant. In our experiments, an enhanced ear number was also found to account for most of the yield compensation that oc- 
Yield compensation (\%)

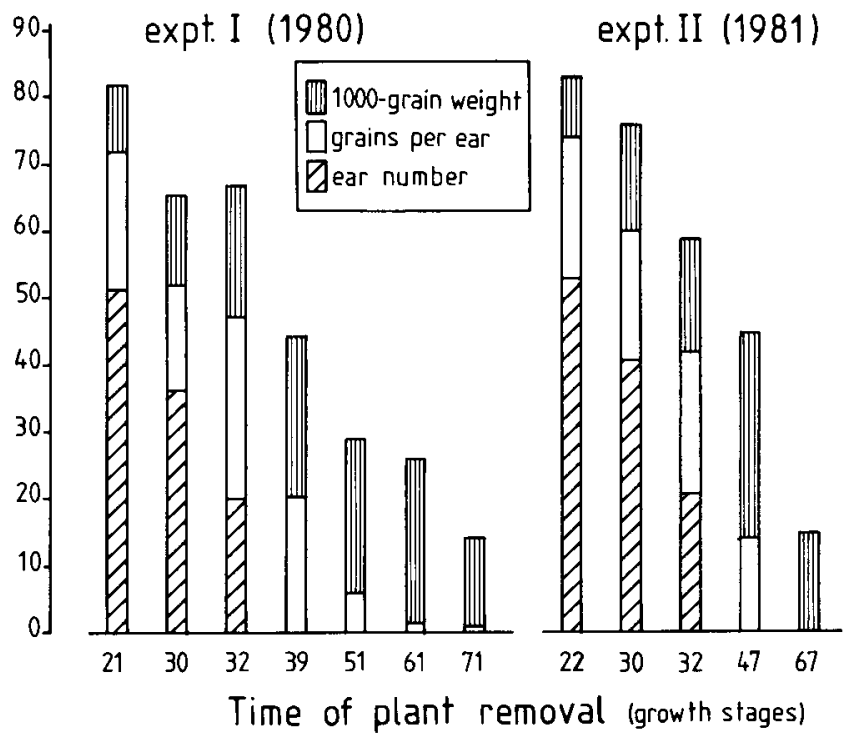

Fig. 1. Compensation for grain yield after removing plants in 2 adjacent rows at different growth stages by ear number, grain number per ear and 1000-grain weight from plants grown in 4 bordering rows.

curred after plants had been removed at an early growth stage (GS 22; see Table 1) or after non-sowing (Table 4). The findings of Austin \& Blackwell (1980) that south-facing rows outyielded north-facing ones was not examined in our experiments.

Yield compensation decreased more the later plants were removed (Table 1). Moreover, the composition of the compensating yield components changed, as is illustrated in Fig. 1. Removing 2 adjacent rows favoured the growth of the plants in the bordering rows, and stimulated those yield components that were initiated from time of removal onwards. Thus, an early removal enhanced all yield components (viz ear number per plant, grain number per ear and 1000-grain weight) and therefore a large compensation in yield could be achieved. With later removal, the contribution of the ear number to yield compensation fell (reaching zero at GS 32); that of the grain number per ear also fell (rearing zero at GS 51). From flowering onwards, yield compensation was small and entirely obtained by an enhanced 1000grain weight. Driving through the wheat crop to carry out various cultural treatments damaged the plants in the wheelings to such an extent that they failed to produce grains. Rows bordering the wheelings, however, compensated for this loss by $56 \%$ to $78 \%$, depending on the number of operations (Table 4). Making pathways by non-sowing two adjacent rows (= tramlines) reduced the yield loss, because yield compensation was higher, ranging from $76 \%$ to $89 \%$. The compensatory effects in the rows bordering wheelings or tramlines resulted in yield losses calculated 
per hectare being less than $150 \mathrm{~kg}$ grain, even after 9 operations (Table 3 ).

Although the yield benefit of deliberately created tramlines vis-à-vis wheelings was small in this experiment, it is worth mentioning that for cultural practices tramlines are easily visible during the entire growing season and they avoid both overlappings and misses.

\section{Acknowledgements}

The author wishes to thank Mr Enoch Boateng from Ghana for technical assistance and Dr Th. Kramer, Dr J. H. J. Spiertz and Dr P. V. Biscoe for critical comments on the manuscript.

\section{References}

Austin, R. B. \& R. D. Blackwell, 1980. Edge and neighbour effects in cereal yield trials. Journal of Agricultural Science, Cambridge 94: 731-734.

Darwinkel, A., 1978. Patterns of tillering and grain production of winter wheat at a wide range of plant densities. Netherlands Journal of Agricultural Science 26: 363-398.

Dilz, K., A. Darwinkel, R. Boon \& L. M. J. Verstraeten, 1982. Intensive wheat production as related to nitrogen: experience in the Benelux. Proceedings of the Fertiliser Society, London 211: 93-124.

Hartmans, D. \& A. Darwinkel, 1982. Het nut van rijpaden in de graanteelt. Landbouwmechanisatie $33(5)$ 477-480.

Miller, J. G. \& N. S. Mountier, 1955. The border row effect in wheat trials with different spacing between plots. New Zealand Journal of Science and Technology, Section A 37: 287-299.

Widdowson, F. V., 1973. Results from experiments with wheat and barley measuring the effects of paths on yield. Experimental Husbandry 23: 16-20.

Zadoks, J. C., T. T. Chang \& C. F. Konzak, 1974. A decimal code for growth stages of cereals. Weed Research 14: 415-421. 